\title{
Moving ahead from food-related behaviours: an alternative approach to understand household food waste generation
}

(1)

(1)

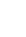

Raquel Diaz-Ruiz: raquel.diaz.ruiz@upc.edu

Jose M. Gil: chema.gil@upc.edu

Center for Agro-Food Economy and Development

Address: Edifici ESAB Parc Mediterrani de la Tecnologia

C/Esteve Terrades, 8 08860-Castelldefels, Barcelona, Spain

Montserrat Costa-Font: montse.costafont@sruc.ac.uk

Land Economy, Environment and Society Research Group

Scotland's Rural College (SRUC)

Address: King's Buildings, West Mains Road, Edinburgh EH9 3JG, United Kingdom

Corresponding author: Raquel Díaz-Ruiz email: raquel.diaz.ruiz@upc.edu

\section{Word count: 8236}

\section{Abstract}

Food waste prevention is a hot topic on the policy agenda. According to available data, urgent measures need to be undertaken to significantly reduce the current generation of food waste.

However, it is important to thoroughly understand consumers' behaviour to define measures that will lead to a long-lasting change in the situation. The aim of the present work is to analyse consumer food waste behaviour by means of a model that brings together food-related and waste management variables. To do so, a survey was given to 418 consumers of the metropolitan area of Barcelona. Results show that food waste is directly influenced by purchasing discipline, waste prevention habits and materialism values and indirectly influenced by environmental values. This highlights the importance of addressing the problem from different perspectives and emphasizes the importance of considering this problem as a transversal element for policy makers. We suggest that household food waste prevention and reduction needs to be included as a key element in different policy areas. 


\section{Highlights}

- Food waste conceptual model incorporating food-related, waste management and consumers' values.

- Waste prevention, purchasing discipline and materialistic values are direct predictors of food waste behaviour.

- Partial least squares (PLS-SEM) validated the consumers’ food waste generation model.

Keywords: food waste, consumer behaviour, structural equation models, waste prevention

\section{Introduction}

The Food and Agricultural Organization of the United Nations (FAO), among other institutions, reported that global limitations on food availability would exist in the upcoming years up to 2050, which, combined with current food waste, results in an unethical and unsustainable world-feeding situation. Food waste is an environmental, economic, social and food security problem (Kosseva, 2013; Stuart, 2009) that urgently needs to be addressed. The United Nations advocates for it within its Sustainable Development Goals. In particular, goal 12.3 states that "By 2030, halve per capita global food waste at the retail and consumer levels and reduce food losses along production and supply chains, including post-harvest losses” (United Nations, 2015). In Europe, reducing food waste is a key area of the circular economy package (European Comission, 2017).

Some work has been done to quantify food waste. FAO’s report in 2011 exposed that one-third of all food produced for human consumption is lost or wasted every year (Gustavsson et al., 2011). In Europe and North America, this equals up to $300 \mathrm{~kg}$ of food per capita and year along the food supply chain. Moreover, published data revealed that about $50 \%$ of the total amount of food is wasted downstream, mainly at the household level (Bio Intelligence Service, 2010; Gustavsson et al., 2011; Katajajuuri et al., 2014; Stenmarck et al., 2016). The most recent study focused on EU-28 reports that $92 \mathrm{~kg}$ of food are discarded per person and year at households where approximately $60 \%$ of its volume is edible (Stenmarck et al., 2016).

Although food waste occurs along the whole supply chain, consumer food waste has been reported to be a hot spot and has received special attention. Different studies have analysed consumers' behaviour, awareness and the causes of food waste in such countries as Greece (Abeliotis et al., 2014), Canada (Parizeau et al., 2015), Romania (Stefan et al., 2013), Denmark (Stancu et al., 2016), the United States (Neff et al., 2015; Qi and Roe, 2016), Italy (Principato et al., 2015; Setti et al., 2016), Singapore (Grandhi and Appaiah Singh, 2015) and New Zealand (Tucker and Farrelly, 
2015). However, despite the increasing interest, the above studies use mainly food-related approaches, leaving waste-related approaches aside. Bearing in mind that the latter is the prevailing approach in food waste prevention campaigns, especially in Europe where food waste legislation is waste oriented (Lucifero, 2016), a more focused analysis on food waste prevention strategies it is necessary in order to identify individual's attitudes, values, behaviours and motivations towards wasting food. Moreover taking into account that food waste is an interdisciplinary issue, it has to be addressed from both waste and food-related perspectives (Kosseva, 2013; Langley et al., 2010). However, the magnitude of the influence of waste and food-related perspectives on consumer behaviour towards wasting food is unknown to date. The aim of the present work is to reach a better understanding of the factors that influence consumers' food waste generation in order to define prevention strategies at the household level and demonstrate that a multidimensional perspective should be undertaken to address the prevention.

Up to date, there has been little attention on the factors driving food waste considering different behavioural dimensions simultaneously. Most of the existing academic literature on food waste either examines a partial dimension or is focused on estimating the amount of food wasted. However, consumer's food waste behaviour is a complex phenomenon build as a result of the interaction of several behavioural aspects. The decision-making process that ends on the behaviour of wasting food is shaped by social, economic and personal factors and is the outcome of the interaction of decisions, values and engagements. One of our contributions to the literature is to design a behavioural framework towards household food waste bringing together the two of the main approaches that define the food waste debate nowadays: waste management and food habits. In addition, we include consumers' values as possible predictors and moderators to complete the model. In particular, we focused on an especially significant region of Europe: the metropolitan area of Barcelona. It is one of the most populated areas of Europe located along the Mediterranean coast, with a growing population accounting for more than 3.2 million people in 2015, and it occupies an area of approximately $636 \mathrm{~km}^{2}, 48 \%$ of which is urbanised (AMB, 2015).

This paper is organised as follows. The next section undertakes a literature review to justify why we hypothesise that a variety of actions and motivators could affect the food waste behaviour, arguing that it is not only a food-related issue but a waste management, an environmental concern and materialistic issue, too. This section summarizes the state of the art regarding food waste behaviour at the household level and develops a conceptual model that explains consumers' food waste behaviour. Section three explains the data and method of analysis. The fourth section of the paper 
reports the main results of the study. Finally, the fifth section discusses the relevance of the results for further research and to define strategies of prevention food waste generation.

\section{Theoretical framework: food waste behaviour}

102 Previous literature demonstrate that food waste does not respond to a single behavioural dimension but emerges from a wide variety of actions and motivators (Evans, 2011; Quested et al., 2013;

104 Secondi et al., 2015; Setti et al., 2016; UNEP, 2014). Due to its complexity, studies to date have only considered partial analysis from diverse disciplines. Watson and Meah (2012) emphasize the dichotomy between the necessity of safe and nutritious food and the desire to reduce food waste. In that line, our theoretical framework advocates for a combined approach assembling current evidences on the relevance of food and environmental behaviours as well as selected consumer values to explain consumers' food waste generation. We aim at testing the power of food-related attitudes, waste-management behaviours and selected values (environmentalism and materialism) to explain consumers' food waste behaviours.

In this section, the paper first attempts to bring together the published evidence from different studies and the distinct identified behaviours towards food waste and to develop a theoretical model considering three main issues: (i) food-related behaviours, (ii) waste management behaviours and (iii) consumers values. It is important to highlight that this research attempts to test that food waste behaviours are not only the results of food related behaviours but of a combination of food unrelated and related behaviours among other elements. Therefore, we did not focus on specific prevention or values regarding food waste, but on general waste prevention habits that we argue could be also related to the generation of food waste.

Household food waste can be considered a food-related behaviour. Some studies intend to determine, by means of different analytical tools, the main causes of food waste generation. The most frequently identified actions that can lead to food waste generation can be grouped in five categories: food purchase, food storage, food preparation, food consumption and lifestyle related to food. Consumers' attitudes, values, knowledge and behaviour towards food might have an effect on the food waste generation (Kosseva, 2013; Parfitt et al., 2010; Principato et al., 2015). We have identified three factors related to food habits: purchasing behaviour, price importance and dietary importance as representatives of food importance towards food waste generation. 
Some studies have found noticeable conceptual links between food waste and food preferences, such as nutrition and food safety (HLPE 2014), dietary conscientiousness (Parizeau et al., 2015), affection for food (Porpino et al., 2016), food preferences (Bio Intelligence Service, 2010; Canali et al., 2014), domestic routines and habits (Evans, 2011) or the social value of food (Mallinson et al., 2016). Indeed, in the Quested et al. (2011) study, people cited eating a healthy diet as an encouraging factor for reducing food waste.

In particular, certain purchasing habits may affect the subsequent household management of food, namely poor planning and shopping routines (Mallinson et al., 2016; Mondéjar-Jiménez et al., 2015; Parizeau et al., 2015; Setti et al., 2016; Stancu et al., 2016; Stefan et al., 2013; Tucker and Farrelly, 2015), excessive buying, (Göbel et al., 2012; Parfitt et al., 2010; Porpino et al., 2015; WRAP et al., 2007) or the symptom of the 'good provider', who is trying to have as much variety as possible for all the household members (Graham-Rowe et al., 2014; Visschers et al., 2016).

Moreover, food price is another element which could have an influence on consumers' food waste generation. This topic has not been studied in detail but some works suggested that marketing attractions such as promotions, also named offer temptation (2x1), can alter consumer's purchase discipline (Mondéjar-Jiménez et al., 2015; Parfitt et al., 2010; Quested et al., 2013; Setti et al., 2016). Moreover, consumer during diverse focus group in Europe pointed out food prices as a possible cause of food generation in the households (Geffen et al., 2016). Finally, Mallinson et al., (2016) described how a group of consumers who reveled higher levels of food cause were more influenced by promotions and were less price-conscious. However, besides these studies, little is known on the relationship between food price importance and food waste generation.

According to the aforementioned studies, we synthesize all food-related causes in three main variables, diet importance, price importance and purchasing discipline. The first three hypotheses are outlined:

- H1: Consumers who reveal a higher concern about the importance of their diet are expected to waste less food.

- H2: The importance that consumers place to food price is expected to have an influence on consumers' food waste (the effect negative or positive cannot be pre/established form the available literature)

- H3: Consumers who reveal a more disciplined purchasing behaviour are expected to waste less food. 
161 Despite the lack of specific studies on food waste behaviours connected with other waste-related activities, some food waste prevention campaigns have emerged from these specific sectors. Regulation of food waste could be characterized as recent and unspecific, even though there are some documents that highlight the urgent need for its reduction. The Waste Framework Directive (WFD-2008/98/EC) (EU, 2008) clearly defines a waste hierarchy (see Fig. 1) and sets a clear waste prevention procedure as a priority. Within the Waste Framework Directive, the distinction between prevention and minimisation could be misunderstood. Therefore, Figure 1 allocates within the waste hierarchy the different preventive measures that encompass prevention, reduction and re-use and waste management measures from recycling to disposal.

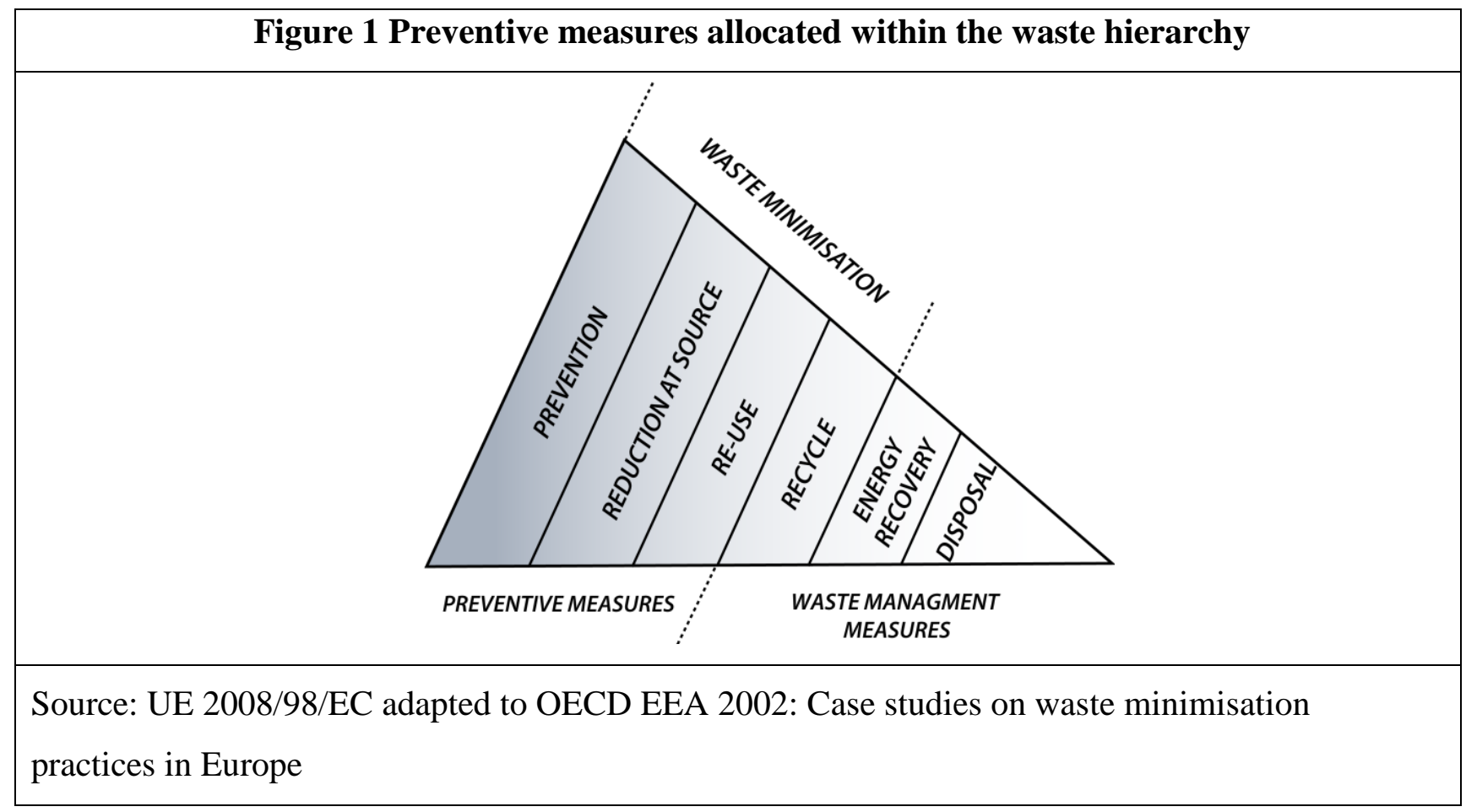

In this sense, to tackle food waste, it is important to differentiate between recycling and prevention concepts. Evidence from the UK indicates that among all strategies to prevent waste, the prevention of food waste is the one with the greatest potential (Cox et al., 2010). There is a specific food waste hierarchy (see Fig. 2) that transposes the hierarchy preferences to food management (European Parliament, 2011; Papargyropoulou et al., 2014). The hierarchy transposes the meanings of prevention, recycling and discarding to food. Thus, first it would be necessary to prevent the generation of food waste. Second, if waste could occur, food should be diverted to humans beforehand. Thirdly, if food cannot be reached by human consumption, it might be used to feed 
animals by conversion of food surplus into feeding. Next, any other industrial uses are proposed such us generation of energy, bio-energy, etc. And the last two levels of food waste recovery hierarchy are food composting and finally landfilling.

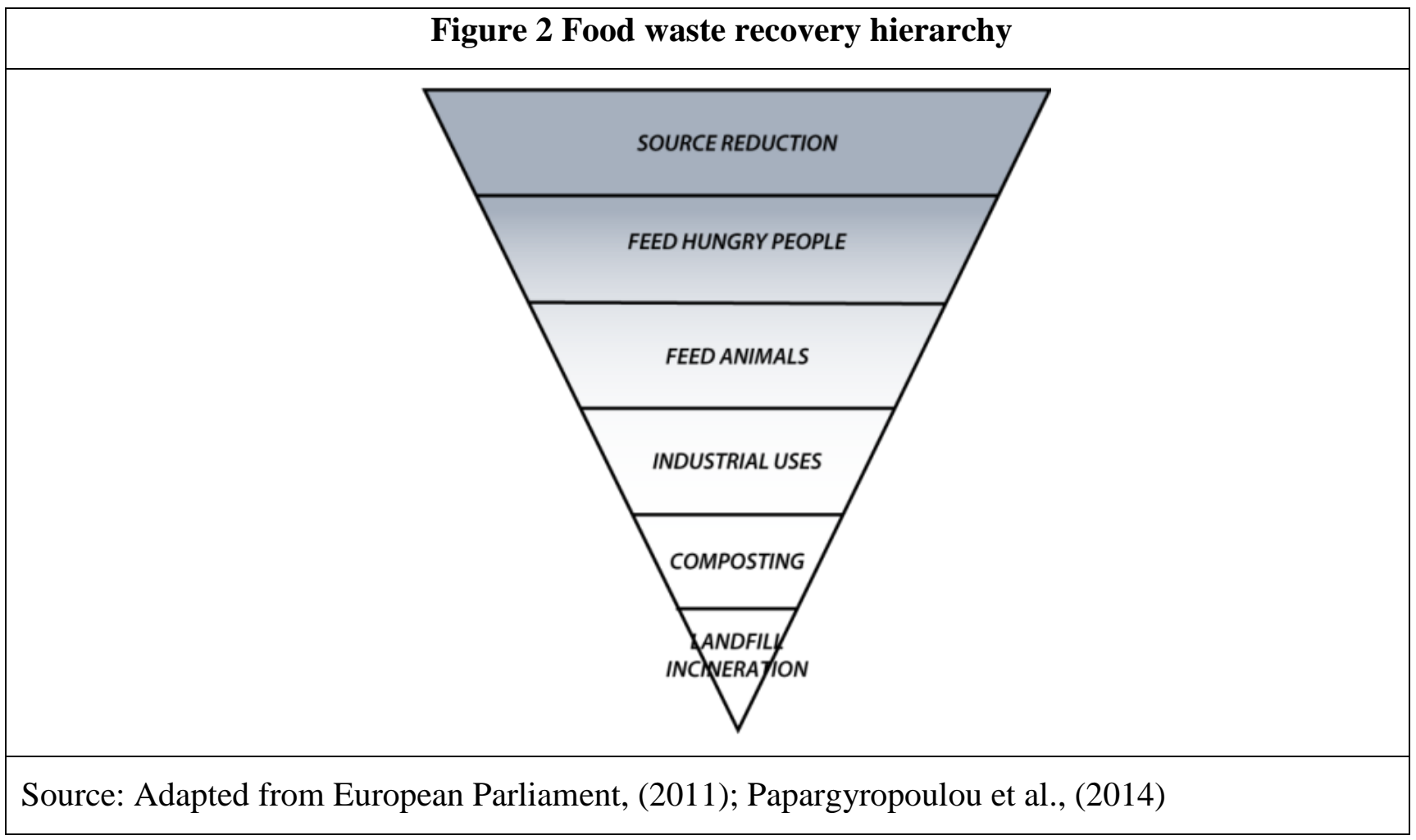

There is a common tendency to relate waste reduction with recycling, although they are not the same concepts. Some examples of waste prevention are the reduction of the amount of plastic employed while shopping such as plastic bags or plastic packaging, repairing objects before buying new ones, re using glass jars, etc. Recycling actions are more commonly known such as recycling plastics, paper, etc. There is a debate in the scientific literature about the relationship between prevention and recycling behaviours. Some authors consider them to be related (Cox et al., 2010) and only the most environmentally encouraged or committed recyclers also act to prevent waste. By contrast, others suggest that waste prevention behaviours are poorly or even negatively correlated with recycling (Barr, 2007; Cecere et al., 2014; Tonglet et al., 2004b). These studies argue that recycling may become a reason for decreasing the effort to reduce waste. Moreover a recent publication found that the positive feelings of recycling can lead to using more quantity of the material needed (Sun and Trudel, 2016). Variables that influence prevention and recycling are diverse. Some authors, such as Barr, (2007); Refsgaard and Magnussen, (2009); Tonglet et al., (2004a); Zorpas and Lasaridi, (2013) suggested that recycling behaviour is influenced primarily by opportunities, facilities and knowledge and, secondly, by not being deterred by issues of physically 
recycling (e.g. time, space, inconvenience). Meanwhile, the factors that influence waste prevention that are most cited in the literature are: universalism values and moral motivations, selfresponsibility to act, self-efficacy, cost, social norms, habits, strong environmental values and knowledge about environmental politics (see Barr, 2007; Cox et al., 2010; Tonglet et al., 2004b). As noted by previous authors the predictors of both are totally different and are quite diverse. Therefore, we considered both behaviours to be distinguished.

Studies like Barr (2007) and Tonglet et al. (2004b) covered the issue of prevention and recycling behaviour in a global scope, without focusing on one single act as in wasting food. More recently, some studies have analysed the influence of food waste disposal, such as the use of the bio-waste container, as an explanatory variable of food waste awareness and behaviour (Tucker and Farrelly, 2015; Visschers et al., 2016).

In the present work, we characterized food waste behaviour as a specific waste management behaviour (Cecere et al. 2014). Prevention and recycling have different consequences, and we want to find out to what extend food waste is influenced by prevention and recycling behaviours.

Thus, the following two hypotheses are considered:

- H4: Consumers who reveal more positive prevention behaviour are expected to reveal lower food waste generation.

- H5: Consumers who reveal more positive recycling behaviour are expected to reveal lower food waste generation.

\subsection{Consumers'values}

Individuals’ environmental concern may be an important indicator impacting food waste behaviour. In fact, recent studies have shown consumers' environmental awareness about food waste consequences (Neff et al., 2015; Principato et al., 2015). In particular, Cecere et al. (2014) indicate a positive effect of Green Attitude on the perceived production of food waste using the Eurobarometer Report of $2011^{1}$ data. Other studies directly link environmental awareness to positive environmental behaviours and waste minimisation (Barr, 2007; Kilbourne and Pickett, 2008; Tonglet et al., 2004a). Taking into consideration the relevance of individual environmental values on the formation of specific waste prevention behaviours we propose the following hypotheses to analyse its indirect and direct effect on food waste behaviour:

\footnotetext{
${ }^{1}$ Flash Eurobarometer 316. Attitudes of Europeans Towards Resource Efficiency
} 
- H6: Consumers who reveal a high environmental concern are expected to demonstrate more positive waste prevention behaviour.

- H7: Consumers who reveal a high environmental concern are expected to demonstrate positive recycling behaviour.

- H8: Consumers who reveal a high environmental concern are expected to report less food waste generation

Finally, consumption habits in general could also influence food waste as mentioned by Parfitt et al. (2010) and WRAP (2007). We include in the model materialism values as a proxy of consumerism. Materialism understood as a value that attaches importance to material possessions and the pursuit of personal wealth (Richins, 2004). The relationship between materialistic values, environmental awareness and behaviour has been clearly established by previous literature. For instance, Hurst et al., (2013) estimated by means of a meta-analysis the correlation between materialism and environmental awareness, and between materialism and environmental behaviour. They noticed that materialism was negatively and equally related with both environmental awareness and environmental behaviours. Also, materialistic values were found to be negatively related to environmental beliefs, and these beliefs influence environmental awareness and environmental responsible behaviour (Kilbourne and Pickett 2008). Based on this evidence, we propose the final hypotheses for the model that states that:

- H9: Individuals’ materialistic values have a negative influence on individuals’ environmental awareness

- H10: Individuals’ materialistic values have a negative influence on individuals’ food waste behaviour.

A theoretical food-waste-values behaviour framework model has been defined (see Fig. 3) by taking into account all the considerations shown above. This model draws some paths of the decisionmaking process that consumers undertake when defining their food waste behaviour.

Figure 3 Theoretical framework of food waste predictors 


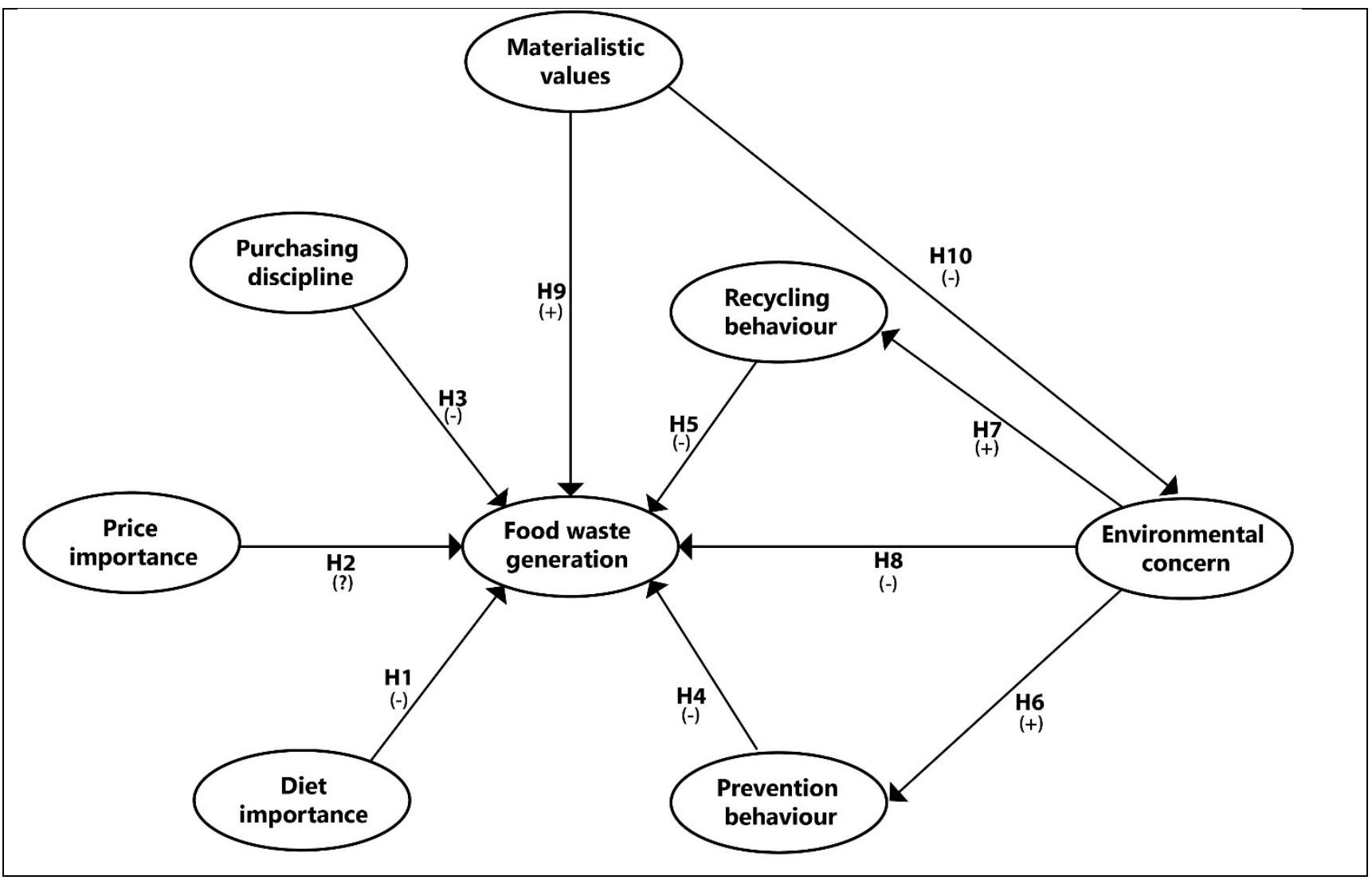

3. Material and methods

\subsection{The sample}

259 We drew our sample from a survey conducted in the metropolitan area of Barcelona (Spain) in 260 autumn 2013. We focused on the subset of consumers who were responsible for cooking or food 261 purchase in their households. We distributed the survey on paper and online through different social media platforms and emails. We finally collected 418 responses. Individuals' characteristics are presented in Table 1 such as gender, age, area of residence, education, income and children in charge (see Table 1). Regarding to the implementation method, the questionnaire was, in most of the cases, self-administrated with available assistance in the case it was required (especially old people needed assistance for reading and understanding how to answer). The survey duration was of about 10 minutes. Both pencil-surveys and online form had the same format and order. 


\begin{tabular}{|c|c|c|}
\hline & Frequency & $\begin{array}{c}\text { \% of } \\
\text { the } \\
\text { sample }\end{array}$ \\
\hline \multicolumn{3}{|l|}{ Gender } \\
\hline Male & 172 & 41.1 \\
\hline Female & 246 & 58.9 \\
\hline \multicolumn{3}{|l|}{ Age $>18$} \\
\hline $18-34$ & 179 & 42.8 \\
\hline $35-49$ & 110 & 26.3 \\
\hline $50-64$ & 102 & 24.4 \\
\hline More than 65 & 28 & 6.5 \\
\hline \multicolumn{3}{|l|}{ Studies } \\
\hline Basics & 84 & 20.1 \\
\hline Medium/superior & 119 & 28.5 \\
\hline Graduate & 211 & 50.5 \\
\hline Dk/na & 4 & 1 \\
\hline \multicolumn{3}{|l|}{ Working status } \\
\hline Employee & 263 & 62.9 \\
\hline Entrepreneur & 36 & 8.6 \\
\hline Pensioner & 40 & 9.6 \\
\hline Unemployed & 71 & 17.0 \\
\hline Dk/na & 8 & 1.9 \\
\hline \multicolumn{3}{|l|}{ Housing structure } \\
\hline Unipersonal & 45 & 10.8 \\
\hline Couple & 106 & 25.4 \\
\hline Family & 234 & 56.0 \\
\hline $\begin{array}{l}\text { Sharing } \\
\text { apartment }\end{array}$ & 33 & 7.9 \\
\hline \multicolumn{3}{|l|}{$\begin{array}{l}\text { Children under } 16 \text { at } \\
\text { home }\end{array}$} \\
\hline None & 292 & 69.9 \\
\hline 1 & 69 & 16.5 \\
\hline 2 & 37 & 8.9 \\
\hline 3 or more & 1 & 1 \\
\hline Dk/na & 16 & 3.8 \\
\hline
\end{tabular}

\subsection{Survey and measures}

275 The questionnaire included 44 questions to build the hypothesized model. A seven-point Likert

276 scale was employed for all questions. Questions scales were in many cases adapted from validated

277 scales such as environmentalism (Dunlap et al., 2000), materialism (Kilbourne and Pickett, 2008;

278 Richins, 2004) and waste recycling and waste prevention (Barr, 2007), the remaining scales were

279 designed by the authors based on previous experience. The final model was formed by 24 indicators

280 due to model specifications explained below. Table 2 summarizes the characteristics of all latent 281 variables and indicators included in the model. It can be observed that the model includes three 
constructs to capture food-related behaviours: purchasing discipline defined by two items, price 283 importance formed by one item and finally importance of diet measured by three indicators. Two four-items constructs were considered for waste-related behaviour, recycling and prevention. Next, two dimensions represented consumer's values on materialism, which included four items, and second environmental concern with two items. Finally, food waste generation included six items.

The survey had a short introduction ${ }^{2}$ asking consumers participation on a food survey. Then, all Agree-Disagree questions (purchasing disciplines, price importance, diet importance, materialism values and environmental concern) were randomly presented, next waste-related questions randomly ordered and finally food waste assessment. Food waste questions were placed at end to avoid interaction between food waste questions and other behaviours under analysis. It has a specific explanation to clarify participants' responses "Following you should think on the amount of food that you have thrown away that otherwise could have been eaten during the past month. Everything which cannot be eaten such as potatoes peels, bones, etc. are not included. You may think on the food that is thrown away through the trash bin, the organic bin, the compost or what you give to your pet.” Both online and paper survey had the same structure.

\subsection{Analytical procedures}

To test relationships among non-observed variables (latent variables) one may opt to use structural equation modelling (SEM) which is a second-generation type of modelling (Fornell and Larcker, 1981; Hair et al., 2014; Kline, 2011). There are two types of SEM, the covariance-based SEM (CBSEM) and the variance based (PLS-SEM). The former is applied to confirm or reject solid theories by estimating the covariance matrix of the data. The latter, is primarily applied in exploratory research to develop new or on early stages theories looking into the variance in the dependent variables (Hair et al., 2014). PLS intends to test how the theory fits the data, the fit of the model in PLS-SEM test the discrepancy between the observed values and the values predicted by the model in question. The objective of PLS is to maximize the variance explained rather than the fit. Due to the novelty approach of combining waste-related, food-related and values-related as a predictors of food waste, we used PLS-SEM to validate the hypotheses formulated above.

PLS technique is gaining adepts due to its flexibility in comparing theory and real data, soft distributional assumptions, its exploratory and prediction-oriented nature, its compatibility with

\footnotetext{
2 Good morning/good afternoon. My name is Raquel Diaz, I am student from the Polytechnic University of Catalonia. We are doing an investigation about food in the metropolitan area. We guarantee complete anonymity of your responses. It would take you around 10 minutes. Could you please collaborate with the study? We appreciate your participation:
} 
311 model complexity and its ease of model interpretation among other. PLS can estimate a model with 312 a large number of latent variables and indicators with small sample sizes (Chin et al., 2008). As 313 noted by Akter et al., (2017), PLS-SEM has been used to analyse more latent variables and 314 including more indicators per model on average than in the CBSEM. In their systematic review, 315 they found that CBSEM accounted for 4.4. latent variables and 14 indicators, whereas PLS 8.12 316 latent variables and 27.42 indicators were included. PLS also gives the flexibility to include one317 single item latent variables, it has no a restriction of at least three-items per latent as in CBSEM.

318 To assess the validity of the model, a two-stage analytical procedure is used. First, the assessment 319 of the measurement model to evaluate the correctness of the latent variables and indicators. And, 320 secondly the structural model relationships and predictive power. Contrary to the CB-SEM, where 321 the two stages are consecutive, the PLS-SEM uses the complete model with the relationships 322 between latent variables from the beginning.

323 Smart PLS (v.3.2.6.) (Ringle et al., 2015) was used to deduce the model. In the following section 324 all the stages and validation statistics are explained in detailed.

\section{Results}

\subsection{Descriptive results}

The first part of this section provides some descriptive results of the different constructs considered in the model. Table 2 summarizes the characteristics of the indicators included in the model, reporting the statements, its mean and standard deviation (SD) as well as the frequency of response distribution within the 7-point Likert scale. These responses have been grouped in three levels: negative from 1-3, neutral 4 and positive form 5-7. We tested the normality of all indicators by means of the Saphiro-Wilk test confirming the non-normal distribution ( $p$-value $=0.000$ ) of all observed variables.

Regarding to food related behaviours, respondents revealed to have a disciplined attitude during shopping. In fact, $60.3 \%$ declared they 'buy only what they need' and they 'do a shopping list' (67.2\%). Consuming cheap food is important for almost half of the sample (52.2\%) and diet seemed

337 to be important in their food choices. Above the $70 \%$ of the sample showed interest in eating food 338 'rich in vitamins' (74.2\%), 'low fat food' (70.8\%) and 'food free of potential hazardous ingredients' 339 (80.4\%). 
340 Regarding to waste recycling and prevention habits, the sample affirmed to have a very high 341 recycling and prevention behaviour. For instance, $82 \%$ of the households do recycle glass, this 342 percentage decreased to $80 \%, 70 \%$ and $60 \%$ in the case of domestic packaging, paper and organic 343 waste, respectively. In terms of waste prevention, both reusing and reduction were included on the 344 survey. The most frequent reusing activity, that $82.3 \%$ of respondents declared to do often or 345 always, was trying to repair things before buying new items as well as reusing paper. On reduction 346 activities the most frequent one was using their own shopping bag.

347 With respect to values, respondents reported low materialism values and high environmental 348 concern. Indeed, they most likely tend to disagree on being happier buying more things or acquiring 349 possessions as a sign of achieving. Furthermore, $75 \%$ of the sample do not agree on admiring 350 people who own expensive homes, cars and clothes. However, almost half of the sample admits that 351 they would be happier if they owned certain things they don't. As regards environmental concern, a 352 high percentage of respondents agree that if things continue on their present course, we will soon 353 experience a major ecological catastrophe (76.8\%). We do not observe the same consensus on the 354 statement 'The so-called “ecological crisis” facing humankind has been greatly exaggerated' where 355 the opinion is more divided and only half of the sample do not agree with it.

356 Concerning food waste generation, most of participants claimed to generate very little food waste 357 (see Fig. 4). The question included the most common situations in where food can be thrown away. 358 The situation with higher mean (2.8 out of 7) is when food has been damaged or moulded.

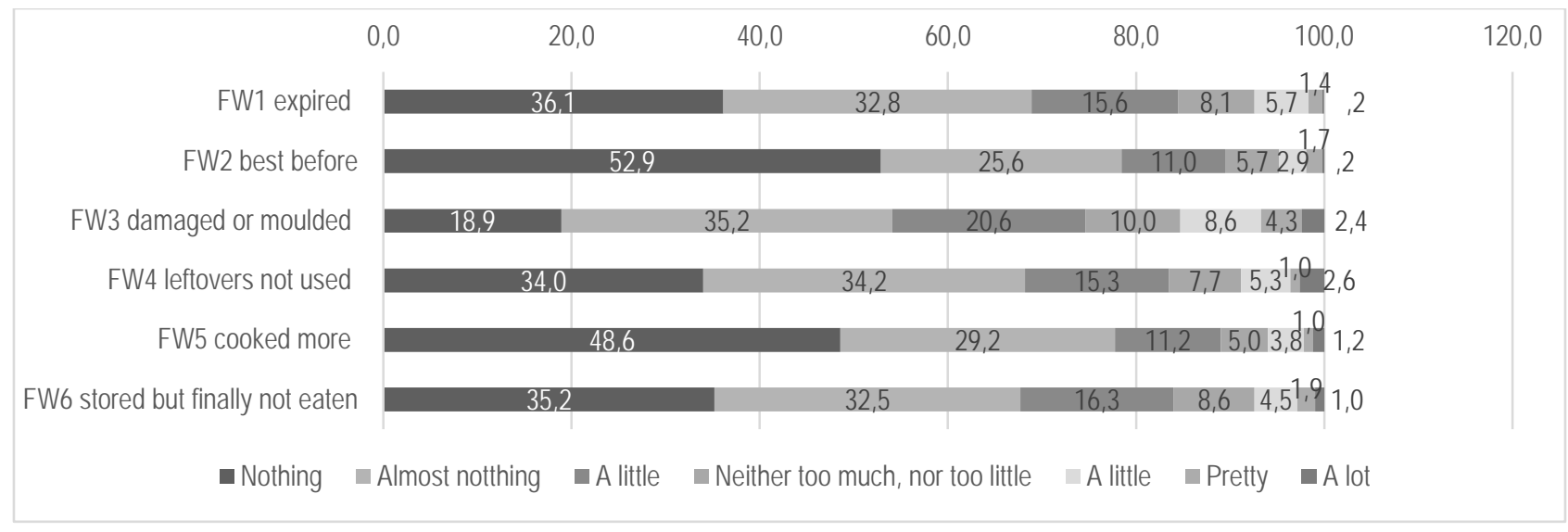




\begin{tabular}{|c|c|c|c|c|c|c|}
\hline \multirow{3}{*}{$\begin{array}{c}\text { Purchasing } \\
\text { discipline (PUR) }\end{array}$} & & \multirow[t]{2}{*}{ Mean } & \multirow[t]{2}{*}{$S D$} & \multicolumn{3}{|c|}{$\begin{array}{l}\text { Distribution within 7- } \\
\text { point Likert scale (\%) }\end{array}$} \\
\hline & & & & $1-3$ & 4 & $5-7$ \\
\hline & \multicolumn{6}{|c|}{ To what extend do you agree with the following statements (1 Totally disagree - 7 Totally agree) } \\
\hline PUR1 & I usually buy only the things I need & 4.8 & 1.7 & 25.6 & 14.1 & 60.3 \\
\hline PUR2 & I do a shopping list with what I need when I go shopping & 5.1 & 2.0 & 22.0 & 10.8 & 67.2 \\
\hline $\begin{array}{l}\text { Price importance } \\
\text { (PI) }\end{array}$ & \multicolumn{6}{|c|}{ To what extend do you agree with the following statements (1 Totally disagree - 7 Totally agree) } \\
\hline PRI1 & It is important to me that food I consume is cheap & 4.4 & 1.7 & 27.3 & 20.6 & 52.2 \\
\hline $\begin{array}{l}\text { Diet importance } \\
\text { (DIET) }\end{array}$ & \multicolumn{6}{|c|}{ To what extend do you agree with the following statements (1 Totally disagree - 7 Totally agree) } \\
\hline DIET1 & Eating food rich in vitamins is important to me & 5.5 & 1.4 & 8.6 & 17.2 & 74.2 \\
\hline DIET2 & Eating low fat food is important to me & 5.2 & 1.6 & 13.4 & 15.8 & 70.8 \\
\hline DIET3 & $\begin{array}{l}\text { Eating food free of potential hazardous ingredients such as } \\
\text { pesticides is important to me }\end{array}$ & 5.8 & 1.7 & 12.4 & 7.2 & 80.4 \\
\hline $\begin{array}{c}\text { Recycling } \\
\text { behaviour (REC) }\end{array}$ & \multicolumn{6}{|c|}{ Could you please indicate how often do you the following? (1 Never - 7 always) } \\
\hline REC1 & I recycle glass & 5.9 & 1.9 & 12.4 & 5.0 & 82.5 \\
\hline REC2 & I recycle paper & 5.6 & 2.0 & 17.0 & 7.2 & 75.8 \\
\hline REC3 & I recycle domestic packaging & 5.8 & 1.9 & 13.2 & 6.0 & 80.9 \\
\hline REC4 & I recycle organic waste & 4.7 & 2.3 & 29.7 & 10.5 & 59.8 \\
\hline $\begin{array}{c}\text { Prevention } \\
\text { behaviour (PREV) }\end{array}$ & \multicolumn{6}{|c|}{ Could you please indicate how often do you the following? (1 Never - 7 always) } \\
\hline RED1 & $\begin{array}{l}\text { I use my own bag when going shopping, rather than one } \\
\text { provided by the shop }\end{array}$ & 5.8 & 1.6 & 10.0 & 7.7 & 82.3 \\
\hline RED2 & $\begin{array}{l}\text { I buy products that can be used again, rather than disposable } \\
\text { items }\end{array}$ & 4.8 & 1.6 & 17.2 & 23.0 & 59.8 \\
\hline REU1 & I try to repair things before buying new items & 5.6 & 1.4 & 6.7 & 11.0 & 82.3 \\
\hline REU2 & I reuse paper & 5.3 & 1.9 & 16.7 & 9.6 & 73.7 \\
\hline $\begin{array}{l}\text { Materialism values } \\
\text { (MAT) }\end{array}$ & \multicolumn{6}{|c|}{ To what extend do you agree with the following statements (1 Totally disagree - 7 Totally agree) } \\
\hline MAT1 & My life would be better if I owned certain things I don't have & 4.3 & 1.9 & 30.1 & 20.6 & 49.3 \\
\hline MAT2 & I'd be happier if I could afford to buy more things & 3.2 & 1.8 & 56.2 & 18.4 & 25.4 \\
\hline MAT3 & I admire people who own expensive homes, cars and clothes & 2.3 & 1.7 & 75.6 & 14.4 & 10.0 \\
\hline MAT4 & $\begin{array}{l}\text { Some of the most important achievements in life include } \\
\text { acquiring possessions }\end{array}$ & 3.4 & 1.8 & 52.6 & 18.4 & 28.9 \\
\hline $\begin{array}{l}\text { Environmental } \\
\text { concern (ENV) }\end{array}$ & \multicolumn{6}{|c|}{ To what extend do you agree with the following statements (1 Totally disagree - 7 Totally agree) } \\
\hline ENV1 & $\begin{array}{l}\text { The so-called "ecological crisis" facing humankind has been } \\
\text { greatly exaggerated }(\mathrm{R})\end{array}$ & 4.8 & 1.9 & 24.9 & 16.5 & 58.6 \\
\hline ENV2 & $\begin{array}{l}\text { If things continue on their present course, we will soon } \\
\text { experience a major ecological catastrophe }\end{array}$ & 5.5 & 1.5 & 11.2 & 12.0 & 76.8 \\
\hline $\begin{array}{c}\text { Food waste } \\
\text { generation (FW) }\end{array}$ & \multicolumn{6}{|c|}{ The amount of food I have thrown away in a recent week because ...(1 Nothing - 7 A lot) } \\
\hline FW1 & it has expired is ... & 2.2 & 1.3 & 84.4 & 8.1 & 7.4 \\
\hline FW2 & it has passed the best before date is... & 1.9 & 1.2 & 89.5 & 5.7 & 4.8 \\
\hline FW3 & $\begin{array}{l}\text { it has been damaged or moulded such as stale bread, etc. is ... } \\
\text { (stored in the fridge or cupboards) }\end{array}$ & 2.8 & 1.5 & 74.6 & 10.0 & 15.3 \\
\hline FW4 & I have leftovers and I have not used them for another meal is ... & 2.3 & 1.4 & 83.5 & 7.7 & 8.9 \\
\hline FW5 & $\begin{array}{l}\text { I cooked more than I needed and I have not used it for another } \\
\text { meal is.... }\end{array}$ & 1.9 & 1.3 & 89.0 & 5.0 & 6.0 \\
\hline FW6 & I had stored from previous meals but finally I have not eaten is... & 2.2 & 1.3 & 84.0 & 8.6 & 7.4 \\
\hline
\end{tabular}


366 The measurement model was validated following the recommendations of (Hair et al., 2014). There 367 are three main stages to do so: the assessment of item reliability, the convergent validity and the 368 discriminant validity. The model consisted on 26 observed variables (OV) forming eight latent 369 variables (LV). The OV excluded from the model did not accomplish the requirements.

\subsubsection{Item reliability}

According to the results showed in Table 3, all latent variables' composite reliability (CR) values are above 0.7 which indicates good internal consistency reliability (Fornell and Larcker, 1981). We opted to rely only on the composite reliability as a measure of the internal consistency, to the detriment of the Cronbach's alpha. Cronbach's alpha tends to underestimate the internal consistency and is sensitive to the number of items involved as well as to the sample measure (Hair et al., 2014; $\mathrm{Xu}$ et al., 2016). In our case, we have a wide range of LV items composition (a single-item, two items LV, etc.), that can affect the results of the statistic. Therefore, we decided to dismiss Cronbach’s alpha criterion from our analysis.

\subsubsection{Convergent validity}

Convergent validity, which explains the positive correlation of a measure with alternative measures of the same construct, was tested by means of the average variance extracted (AVE). To do so, we first analyse the outer loadings of every indicator and second, we assessed the AVE's values for the LV. All indicators outer loadings are statistically significant as it is shown in Table 3, see t-values (the common used critical values for two-tailed test are 1.96 with 5\% of significant level). In addition, most of the outer loadings are above 0.7 which means that the variance shared between the construct and the indicator is larger than the measurement error variance. There are seven outer loadings bellow that rule of thumb, however they are above 0.5. As pointed out by, Hair et al., (2014) citing Hulland, (1999) in social sciences when new scales are developed it is frequent to obtain lower outer loadings. Moreover, we have implemented the outer loading relevance testing for indicators with an outer loading below 0.7. Since the deletion of the outer loading below 0.7 has not increased the AVE and CR we decide to keep those indicators in the model. For a single-item construct (Price importance), the AVE is not an appropriate measure as the outer loading is fixed at 1.00. All of AVE are above 0.5, which indicates that the construct explains more than half of the variance of its indicators and therefore satisfies the criteria of convergent validity (Fornell and Larcker, 1981). 
Table 3 Reliability measurements

\begin{tabular}{|c|c|c|c|c|}
\hline & $\begin{array}{l}\text { outer } \\
\text { loading }\end{array}$ & $\begin{array}{c}\text { t-statistic } \\
\text { outer } \\
\text { loading }\end{array}$ & $\begin{array}{l}\text { Composite } \\
\text { Reliability }\end{array}$ & $\begin{array}{c}\text { Average } \\
\text { Variance } \\
\text { Extracted } \\
\text { (AVE) }\end{array}$ \\
\hline Purchasing discipline (PUR) & & & 0.774 & 0.631 \\
\hline PUR1 & 0.818 & 11.056 & & \\
\hline PUR2 & 0.770 & 8.779 & & \\
\hline Price importance (PI) & & & 1.000 & 1.000 \\
\hline PRI1 & 1.000 & & & \\
\hline Diet importance (DIET) & & & 0.783 & 0.548 \\
\hline DIET1 & 0.757 & 4.835 & & \\
\hline DIET2 & 0.803 & 6.356 & & \\
\hline DIET3 & 0.653 & 4.512 & & \\
\hline Recycling behaviour (REC) & & & 0.936 & 0.786 \\
\hline REC1 & 0.916 & 61.966 & & \\
\hline REC2 & 0.915 & 72.756 & & \\
\hline REC3 & 0.943 & 101.263 & & \\
\hline REC4 & 0.761 & 24.994 & & \\
\hline Prevention behaviour (PREV) & & & 0.807 & 0.512 \\
\hline RED1 & 0.664 & 12.243 & & \\
\hline RED2 & 0.726 & 17.624 & & \\
\hline REU1 & 0.720 & 14.021 & & \\
\hline REU2 & 0.749 & 17.922 & & \\
\hline Materialism values (MAT) & & & 0.814 & 0.531 \\
\hline MAT1 & 0.594 & 6.693 & & \\
\hline MAT2 & 0.849 & 25.824 & & \\
\hline MAT3 & 0.851 & 24.844 & & \\
\hline MAT4 & 0.572 & 5.719 & & \\
\hline Environmental concern (ENV) & & & 0.723 & 0.589 \\
\hline ENV1 & 0.960 & 13.417 & & \\
\hline ENV2 & 0.506 & 2.459 & & \\
\hline Food waste generation (FW) & & & 0.888 & 0.572 \\
\hline FW1 & 0.641 & 10.379 & & \\
\hline FW2 & 0.693 & 12.444 & & \\
\hline FW3 & 0.749 & 19.696 & & \\
\hline FW4 & 0.811 & 31.439 & & \\
\hline FW5 & 0.807 & 21.314 & & \\
\hline FW6 & 0.818 & 24.361 & & \\
\hline
\end{tabular}

\subsubsection{Discriminant validity}

399 As shown in Table 5, the discriminant validity is satisfied. We examine cross loadings of the 400 indicators to asses to what extend every LV is different from the others, say they are measuring 401 different things. We applied the Fornell-Larcker criterion where we compare the square root of the 402 AVE values (in bold in the diagonal) with the latent variable correlation (off-diagonal).

403 We tested the possibility of having the prevention behavior break up in two dimensions measured 404 by different constructs as proposed by Barr (2007) in the original scale. However, we detected 405 problems of discriminant validity between them. Thus, both reusing and reducing behaviours have 

between every pair of LV was between recycling behaviour and prevention behaviour $(\mathrm{r}=0.539)$.

\begin{tabular}{|c|c|c|c|c|c|c|c|c|}
\hline & DIET & ENV & FW & MAT & PRE & PI & PUR & REC \\
\hline DIET & $\mathbf{0 . 7 4 0}$ & & & & & & & \\
\hline ENV & 0.076 & $\mathbf{0 . 7 6 7}$ & & & & & & \\
\hline FW & -0.144 & -0.048 & $\mathbf{0 . 7 5 6}$ & & & & & \\
\hline MAT & -0.120 & -0.151 & 0.248 & $\mathbf{0 . 7 2 9}$ & & & & \\
\hline PRE & 0.306 & 0.236 & -0.382 & -0.293 & $\mathbf{0 . 7 1 5}$ & & & \\
\hline PI & 0.160 & -0.085 & 0.067 & 0.210 & -0.028 & $\mathbf{1 . 0 0 0}$ & & \\
\hline PUR & 0.275 & 0.029 & -0.253 & -0.157 & 0.336 & 0.096 & $\mathbf{0 . 7 9 4}$ & \\
\hline REC & 0.183 & 0.170 & -0.287 & -0.288 & 0.539 & -0.026 & 0.290 & $\mathbf{0 . 8 8 7}$ \\
\hline
\end{tabular}

Diagonals in bold represent the square root of each construct's AVE. Off-diagonals are the latent variable correlations.

been considered under the same latent variable called prevention ${ }^{3}$. The higher correlation found

\section{Table 5 Fornell-Larcker test of discriminant validity}

\subsection{Structural model evaluation}

Once we have established the reliability and validity of the constructs we proceed to examine the structural model which estimates hypothesized paths between exogenous and endogenous latent constructs. It was evaluated by collinearity assessment, path significance, coefficient of determination and the predictive accuracy.

The first step is to assess structural model for collinearity issues. In the proposed model there were no presence of co-linearity in the structural model since all Variance Inflation Factors are below the critical value of 5 (Hair et al., 2014).

PLS is a non-parametric technique. Thus, the bootstrapping procedure needs to be applied to obtain the significance of the paths. A 5000 sub-samples bootstrapping was applied to compute the empirical $t$ values of the relationships in the model. Table 6 shows the path coefficients of all hypotheses and its t-values with the associated p-value. From the results, we can support hypotheses 4, 9 and 3. That is, there is a significant and negative association between waste

\footnotetext{
${ }^{3}$ A factor analysis was employed to decide if reusing and reducing behaviours can be included in a common factor. A principal component analysis was conducted on the 8 items with oblique rotation (direct oblim). The Kaiser-MeyerOkin measure verified the sampling adequacy for the analysis, $\mathrm{KMO}=0.851$. Two factors have eigenvalues over Kaiser's criterion of 1 and in combination explained $65.6 \%$ of the variance. The pattern matrix after rotation reveals two factors representing recycling and prevention. As regards of reduction and reusing variables it is confirmed that they are not statistically different dimensions.
} 
423 prevention and food waste (path coeff. $=-0.272$, t-value $=4.493$ ), a significant and positive 424 association between materialism values and food waste (path coeff. $=0.124$, t-value 2.504) and 425 finally a significant and negative association between purchasing discipline and food waste. On the 426 contrary, hypotheses 1, 2, 5 and 8 cannot be supported. Non-significant results were found for the 427 negative and direct association between diet importance and food waste (path coeff. $=-0.011$, $\mathrm{t}$ 428 value=0.216), the direct and positive association between price importance and food waste (path 429 coeff. $=0.049$, t-value $=1.011$ ), the direct and negative association between recycling behaviour and 430 food waste (path coeff. $=-0.075$, $\mathrm{t}$-value $=1.205$ ) and finally the direst and positive association 431 between environmental concern and food waste (path coeff. $=0.056$, $\mathrm{t}$-value $=1.023$ ). With regard to 432 other model paths, we can observe a significant relation between materialism values and 433 environmental concern (path coeff. $=-0.151$, t-value=2.339) supporting hypothesis 10. Finally, 434 environmental concern was significantly, directly and positively linked with both prevention 435 behaviour (path coeff. $=0.236$, $\mathrm{t}$-value $=4.383$ ) hypothesis 6 and recycling behaviour (path coeff. = 436 0.170, t-value=3.229) hypothesis 7. All in all, six out of ten hypotheses were supported. Figure 5 437 presents a summary of the measurement and structural model.

Table 6 Significance analysis of the structural model

\begin{tabular}{|c|c|c|c|c|}
\hline Hypotheses & Path & $\begin{array}{c}\text { Path } \\
\text { coefficient }\end{array}$ & t-value & $\boldsymbol{p}$-value \\
\hline H1 & DIET $\rightarrow$ FW & -0.011 & 0.216 & 0.829 \\
\hline H2 & PI $\rightarrow$ FW & 0.049 & 1.011 & 0.312 \\
\hline H3 & PUR $\rightarrow$ FW & -0.124 & 2.539 & 0.011 \\
\hline H4 & PRE $\rightarrow$ FW & -0.272 & 4.450 & 0.000 \\
\hline H5 & REC $\rightarrow$ FW & -0.075 & 1.205 & 0.228 \\
\hline H6 & ENV $\rightarrow$ PRE & 0.236 & 4.383 & 0.000 \\
\hline H7 & ENV $\rightarrow$ REC & 0.170 & 3.229 & 0.001 \\
\hline H8 & ENV $\rightarrow$ FW & 0.056 & 1.023 & 0.307 \\
\hline H9 & MAT $\rightarrow$ FW & 0.124 & 2.398 & 0.017 \\
\hline H10 & MAT $\rightarrow$ ENV & -0.151 & 2.339 & 0.019 \\
\hline
\end{tabular}

Finally, the overall potential explanatory power of food waste generation in the model equals $19.0 \%$ 441 (R2=0.190), which is similar to the values found in previous studies analysing waste prevention 442 behaviour (Barr, 2007; Stancu et al., 2016). Low coefficient of determination values as 0.20 can be 443 considered high in the consumer behaviour discipline (Hair et al., 2011; Henseler et al., 2009). All 444 coefficient of determination $\mathrm{R}^{2}$ values of the latent constructs are shown in Table 7. The power in 445 predicting the rest of exogenous LV is weak, below $6.8 \%$ of the variance explained. Yet, by examining the predictive accuracy of the endogenous constructs by means of Stone-Geisser's Q2 
447 value we confirmed the predictive relevance of every endogenous construct in the model

448 (Environment concern $=0.008$, Food waste $=0.090$, Prevention $=0.025$ and Recycling $=0.020)$. To 449 assess the $\mathrm{Q}^{2}$ values a blindfolding procedure needs to be applied (see Hair et al., (2014)for details).

450 Values larger than zero indicate a satisfactory predictive relevance. Finally, environmental concern 451 has a significant indirect effect towards food waste through recycling and prevention $(0.077$, p452 value $=0.001)$.

Table 7 Coefficient of determination and predictive relevance of endogenous latent variables

\begin{tabular}{|c|c|c|}
\hline & $\mathbf{R}^{\mathbf{2}}$ & $\mathbf{Q}^{\mathbf{2}}$ \\
\hline Environmental concern (ENV) & 0.023 & 0.008 \\
\hline Food waste generation (FW) & 0.190 & 0.090 \\
\hline Prevention behaviour (PREV) & 0.056 & 0.025 \\
\hline Recycling behaviour (REC) & 0.029 & 0.020 \\
\hline
\end{tabular}

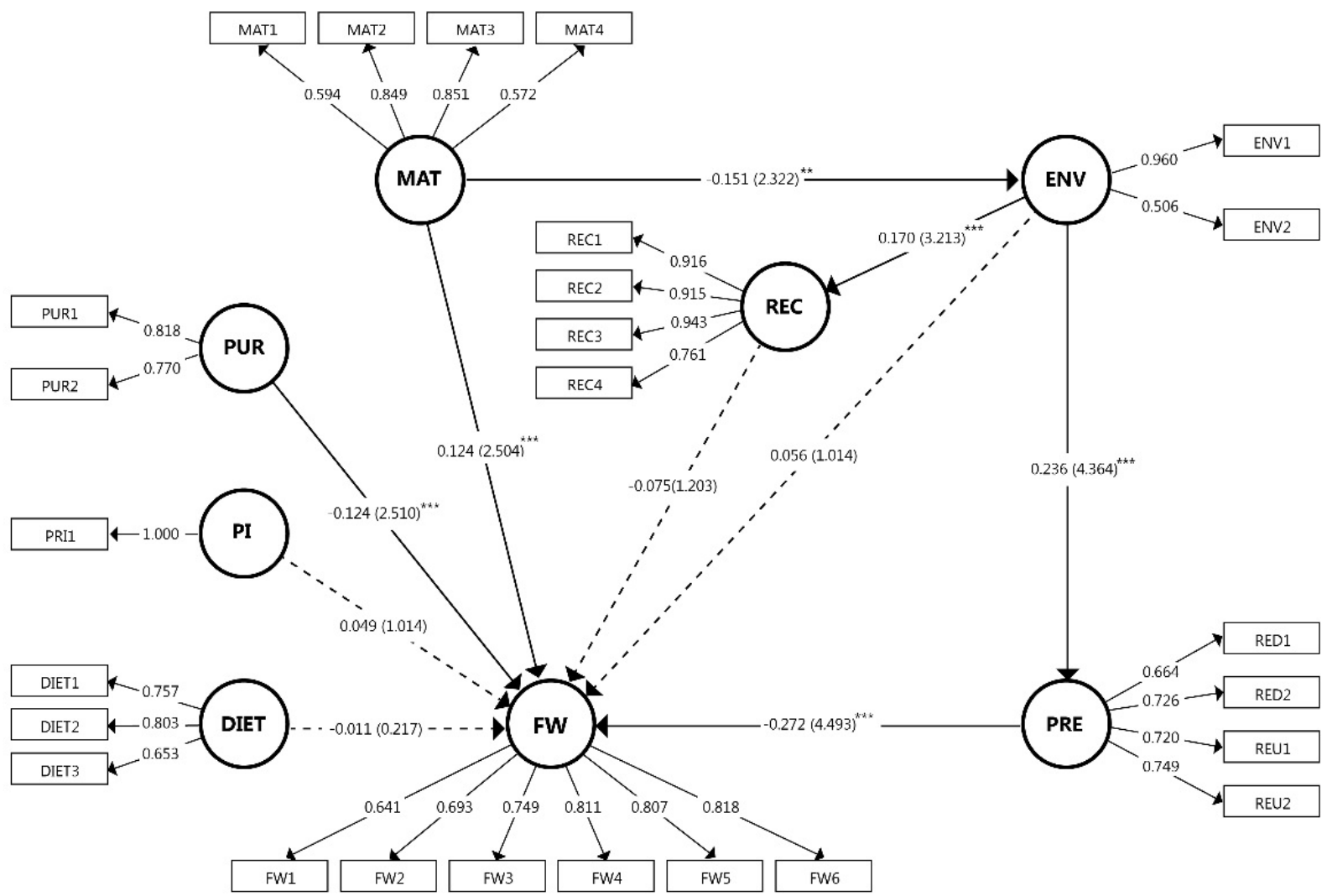




\section{Discussion and conclusions}

460 Over the past decade, many public institutions such as FAO, UN, the European commission or 461 USDA among others together with NGOs and further stakeholders have alerted the society about 462 the increasing amount of food being produced but not eaten. Some reports intended to quantify the 463 amount of food lost or wasted within the different stages of the food chain reaching the conclusion 464 that households are important points to be assessed due to the big amount of waste that they 465 generate. In order to reduce household food waste a better understanding of the reasons that build consumers food waste behaviour is needed. Up to now a big part of the food waste literature is focused on the analysis of consumers' food attitudes to explain food waste behaviours. However, we argue that the environmental dimensions of consumers' actions together with consumer values can also play an important role in that behavioural process. To do that we developed a model that combine food-related and waste-related behaviours together with environmental and materialism values to explain household food waste behaviours.

It is the first time, to our knowledge, that food-related and waste-related behaviours and environmental and materialism values are used in the same model to predict food waste generation. To do the analysis we employed PLS-SEM, classified as soft modelling techniques where the exploratory nature of the models prevails to the confirmatory one. The results obtained from our model confirmed our hypothesis that food waste behaviour is a complex issue that needs to be analysed with an integrative approach. Overall, the main results of the present study suggest that consumers' purchasing discipline, waste prevention behaviours and materialism values are useful direct predictors of food waste behaviour. Specifically, high and committed waste prevention behaviour influences to declare low food waste generation. Also, a disciplined purchasing behaviour - namely doing a shopping list or buying only what it is needed - also predicts lower food waste generation. Finally, the higher the materialistic values a consumer has the higher the amount of food waste he/she declares to generate. Moreover, we want to highlight that all three factors resulted equally important to predict food waste. In addition of the direct predictors indirect relations have also been identified. This is the case of environmentalism concern, that indirectly influence food waste perceived behaviour through waste prevention. Finally, we cannot assure that recycling behaviour, price and diet importance have an influence on food waste behaviour.

\subsection{Research implications}

489 We contribute to the literature supporting previous research mentioned in section 2 and developing 490 a new angle for the understanding of household food waste generation. New variables considered 
491 are consumers' purchasing discipline, price importance and diet importance. We are aware that recent studies demonstrated that other food factors such as date labelling knowledge and preference, 493 planning, marketing sale attractions or leftovers management are also important to undertint the 494 formation of consumers' food waste behaviour. Therefore, we suggest a further analysis must be performed consider all those factors together

496 Another contribution refers to the recognition of a relation between high environmental concern and 497 positive recycling behaviour contrary to previous work Barr (2007); Refsgaard and Magnussen 498 (2009); Tonglet et al. (2004a) who noticed that individuals' recycling behaviour is not conditioned 499 by their environmental values and does not determine their waste behaviour. With our results, we 500 cannot ensure that recycling has a predictive effect on food waste generation. It is interesting to 501 highlight that our model reveals a lack of differentiation between two dimensions of waste prevention behaviour that have been considered in other works as conceptually different. Waste reducing and prevention have been jointly treated in this study for three main reasons. First, Barr, (2007), in his seminal paper, already indicated that both variables are very similar in people's mind. Second, previous research carried out in Catalonia (Díaz-Ruiz et al., 2015) corroborated this idea. Third, a discriminant analysis validated it. For future studies, it would worth it keep them separate it in order to evaluate the evolution through time. Moreover, other regions from Europe with other waste management background might have different outcomes.

509 This paper also contributes to the literature by relating materialism with environmentalism concern 510 and with a specific environmental behaviour as food waste generation. The relationship between 511 materialism and environmentalism is negative and significant confirming evidences from Hurst et 512 al.,(2013) meta-analysis and Kilbourne and Pickett's (2008). We also tested in the same model, as 513 recommended by Hurst et al., (2013), a direct relationship between environmentalism values and 514 food waste generation. The relationship was positive and with almost the same intensity than 515 towards environmental concern. These relationships are important, significant and negative, 516 supporting Hurt et al. Moreover our model also supports the studies that relate consumerism culture 517 life with food waste (Parfitt et al., 2010; WRAP et al., 2007; WRAP and Quested, 2009).

518 Finally, it is important to take into account that consumer behaviour is measured on a self-report 519 basis. As seen in Figure 6, people tend to answer that they do not generate food waste, or only a 520 little. Interestingly, results coincide with the answer about the amount of food wasted in the 521 Eurobarometer Flash EB Series 316 (European Commission, 2011), in which 71\% of respondents 522 believe they throw away less than 15\% (is the answer with the lowest percentage) of the food they buy. In addition, in the latest version of Euro Barometer Flash EB Series 388 (European 
524 Commission, 2014), people tend to say that they generate less food waste than in 2011. It seems 525 that this is a general trend in consumer food waste self-reporting. In Neff et al., (2015) 73\% of the sample reported that they discarded less than the average American, or, in Mondéjar-Jiménez et al.,

527 (2015), more than 75\% of both groups in Italy and Spain reported that they waste none or up to 15\% 528 of the food (the second category available) that they purchased. The lack of official and cross529 sectional data makes it difficult to evaluate if the estimations of consumers are correct. There is a 530 debate on the literature between the positive and negative effects of self-reporting. On the one hand, 531 Kormos and Gifford (2014) argue that there is a great variance (79\%) between the objective 532 behaviour and the self-reported, which remains unexplained. And, on the other hand, Milfont 533 (2009) advocates the lack of empirical studies testing the effect of social desirability on self534 reported environmental attitudes and ecological behaviour. We suggest testing different typologies 535 of consumer food waste self-reporting and comparing those tests with real data for future studies. 536 Improving the dependent variable variance will improve the predictive power of the models.

537 We encourage researchers to include variables from both perspectives, food and waste management 538 to analyse consumers' food waste behaviour and to deepen in other cultural values such as 539 materialism. Statistical modelling and consumers' studies have their limitations on the number of 540 constructs we can capture from a single sample - such as the length of surveys, the cost of 541 collecting data or the statistical performance of multiple hypotheses at the same time. However, 542 there is a wide literature contributing to fill the gaps and improve the models. Our aim with this 543 study was two-fold contributing to the academic literature and providing evidences to policy makers 544 to better address food waste prevention. On the former we acknowledge the need for further 545 empirical evidence and we encourage other researcher to include the variables proposed in the present model to their future studies, prioritizing waste prevention, shopping discipline and materialism values.

\subsection{Policy implications}

549 Given the urgency of the situation, structural changes need to be done to achieve significant 550 reductions of food waste as indicated by the United Nations' SDGs. To do so, we encourage 551 policymakers to treat the issue using a multiple dimension strategy, and involving as much expertise 552 as possible to embrace the whole complexity of the food waste conundrum. Using this type of 553 approach behavioural changes may be reached and last over time moving consumer to construct a 554 more sustainable society. 
We want to highlight the relevance of the prevention behaviour for food waste reduction. We perceive that prevention behaviour is a complex issue very often confused with recycling behaviours. Nevertheless, to prevent is not the same as to recycle, and the food waste prevention campaigns should address the first in order to reduce waste generation. In addition, European environmental legislation (UE 2008/98/EC) recommends to perform prevention actions as the first option in the hierarchy to manage waste, as shown in Figure 1, but to date it does not receive sufficient attention. As cited by the House of Lords (2014) according to FareShare ${ }^{4}$ : 'at the moment, we have a waste hierarchy that is completely out of kilter with the economic hierarchy that sits alongside it'. It could create the temptation to prioritize energy recovery over redistribution or prevention. Researchers and policy institutions should be able to facilitate the first stages of the food waste prevention pyramid (see Fig. 3) by providing evidence and promoting certain regulations to encourage food waste prevention. Campaigners might be careful not to confuse consumers with the concepts of recycling, sorting or composting with prevention and not generation of waste. Sorting organic waste or composting at home could be seen as a way of being more concerned about food waste, but research on this specific topic is needed to find out the effect of food sorting.

In Europe, food waste prevention emerged from waste sectors. As Lucifero (2016) pointed out food waste definition in Europe is more environmentally oriented and especially waste oriented. This fact could influence food waste prevention initiatives, but our research encourages policymakers to pay greater attention to food-related variables on food waste prevention campaigns. Notwithstanding, simplifying it to mere tips on food management could be counterproductive. The results of our survey and a previous one in the same region (Díaz-Ruiz et al., 2015) revealed high self-evaluations in purchasing discipline, for example, making a shopping list, organizing the fridge or developing cooking skills. Indeed, changing prevention behaviours is not as easy as influencing recycling behaviours, as demonstrated in different studies to date. Prevention behaviours are influenced by a set of actions and values distant from materialistic or direct economic issues. Furthermore, food waste prevention, in particular, could be even more complex than other behaviours, such as energy efficiency in households. As explained by Quested et al. (2013), turning off the lights has a direct consequence, seen by the user (reducing the light bill, for instance), that food waste reduction does not have. Food waste consequences happen outside of home and could be diverse: economic, social and environmental among others. We finally recommend including the discussion of current consumerism lifestyle into the debate. And to include values-based campaigns in the food waste

\footnotetext{
${ }^{4}$ http://www.fareshare.org.uk/
} 
prevention agenda as previously proposed by other authors in the environmental field (Hurst et al., 2013). This could be translated in proposing less resources consuming lifestyles, more frugality related to decrease materialism values of individuals.

\subsection{Final remark}

591 To achieve the goal of reducing global food waste, special attention needs to be paid to individual 592 households. It is necessary to understand consumers' behaviour and attitudes towards food waste 593 generation and prevention. Since wasting food is caused by multiple factors, this paper proposes a 594 model to encourage both researchers and policymakers to broaden the perspectives and combine a 595 diversity of approaches to depict factors influencing the generation of food waste. And eventually, 596 more appropriate and effective solutions will be designed.

\section{Acknowledgements}

This study was partially financially supported by the Metropolitan Area of Barcelona Prevention Grants. RDR has a pre-doctoral research grant from the Spanish Ministry of Education (FPU 13/06077).

\section{References}

Abeliotis, K., Lasaridi, K., Chroni, C., 2014. Attitudes and behaviour of Greek households regarding food waste prevention. Waste Manag. Res. 32, 237-40. doi:10.1177/0734242X14521681

Akter, S., Fosso Wamba, S., Dewan, S., 2017. Why PLS-SEM is suitable for complex modelling? An empirical illustration in big data analytics quality. Prod. Plan. Control 28, 1011-1021. doi:10.1080/09537287.2016.1267411

AMB, 2012. Àrea metropolitana - URL http://www.amb.cat/s/home.html (accessed 7.21.14).

Barr, S., 2007. Factors Influencing Environmental Attitudes and Behaviors: A U.K. Case Study of Household Waste Management, Environment and Behavior. doi:10.1177/0013916505283421

Bio Intelligence Service, 2010. Preparatory Study on Food Waste Across EU 27. doi:10.2779/85947

Canali, M., Östergre, K., Amani, P., 2014. Drivers of current food waste generation , threats of future increase and opportunities for reduction. Bologna. 
Cecere, G., Mancinelli, S., Mazzanti, M., 2014. Waste prevention and social preferences: the role of intrinsic and extrinsic motivations. Ecol. Econ. 107, 163-176. doi:10.1016/j.ecolecon.2014.07.007

Chin, W.W., Peterson, R.A., Brown, S.P., 2008. Structural Equation Modeling in Marketing: Some Practical Reminders. J. Mark. Theory Pract. 16, 287-298. doi:10.2753/MTP1069-6679160402

Cox, J., Giorgi, S., Sharp, V., Strange, K., Wilson, D.C., Blakey, N., 2010. Household waste prevention--a review of evidence. Waste Manag. Res. 28, 193-219. doi:10.1177/0734242X10361506

Díaz-Ruiz, R., Costa-Font, M., Gil, J.M., 2015a. A social perspective on food waste: to what extent consumers are aware of their own food waste, in: Escajedo San-Epifanio, L., De Renobales Scheifler, M. (Eds.), Envisioning a Future without Food Waste and Food Poverty. Wageningen Academic Publishers, pp. 157-164. doi:doi:10.3920/978-90-8686-820-9_18

Dunlap, R.E., Van Liere, K.D., Mertig, A.G., Jones, R.E., 2000. New Trends in Measuring Environmental Attitudes: Measuring Endorsement of the New Ecological Paradigm: A Revised NEP Scale. J. Soc. Issues 56, 425-442. doi:10.1111/0022-4537.00176

EU, 2008. DIRECTIVE 2008/98/EC OF THE EUROPEAN PARLIAMENT AND OF THE COUNCIL of 19 November 2008 Directives on waste and repealing certain. European Parliament, European Union.

European Comission, 2017. Communication from the commission to the european parliament, the council, the european economic and social committee and the committee of the regions. Closing the loop - An EU action plan for the Circular Economy COM/2015/0614 final.

European Commission, 2011. Flash Eurobarometer Series 316, Attitudes of Europeans towards resource efficiency Analytical report Attitudes of Europeans towards resource efficiency.

European Commission, 2014. Flash Eurobarometer 388 (Attitudes of Europeans Towards Waste Management and Resource Efficiency). doi:10.2779/14825

European Parliament, 2011. Report in how to avoif food wastage: strategies for a more efficient foos chain in the EU (2011/2175(INI)) Committee on Agriculture and Rural Development Rapporteur: Slavatore Caronna.

Evans, D., 2011. Blaming the consumer - once again: the social and material contexts of everyday 
food waste practices in some English households. Crit. Public Health 21, 429-440. doi:10.1080/09581596.2011.608797

Fornell, C., Larcker, D.F., 1981. Evaluating Structural Equation Models with Unobservable Variables and Measurement Error. J. Mark. Res. 18, 39. doi:10.2307/3151312

Geffen, L. van, Sijtsema, S.J., Újhelyi, K., Eisenhauer, P., Diedrich, A.-C., Brumbauer, T., DíazRuiz, R., López-i-Gelats, F., Reinoso Botsho, D., Winter, M. van H., Herpen, E. van, 2016. National , Qualitative insight on Household \& Catering Food Waste. Wageningen, Netherlands Wageningen Univ. Econ. Res. 193.

Göbel, C., Teitscheid, P., Ritter, G., 2012. Reducing Food Waste - Identification of causes and courses of action in North. Müntser.

Graham-Rowe, E., Jessop, D.C., Sparks, P., 2014. Identifying motivations and barriers to minimising household food waste. Resour. Conserv. Recycl. 84, 15-23. doi:10.1016/j.resconrec.2013.12.005

Grandhi, B., Appaiah Singh, J., 2015. What a Waste! A Study of Food Wastage Behavior in Singapore. J. Food Prod. Mark. 22, 1-16. doi:10.1080/10454446.2014.885863

Gustavsson, J., Cedeberg, C., Sonesson, U., Otterdijk, R. van, Meybeck, A., 2011. Global food losses and food waste - Extent, causes and prevention. Rome.

Hair, J.F., Ringle, C.M., Sarstedt, M., 2011. PLS-SEM: Indeed a Silver Bullet. J. Mark. Theory Pract. 19, 139-152. doi:10.2753/MTP1069-6679190202

Hair, J.F.J., Hult, G.T.M., Ringle, C., Sarstedt, M., 2014. A Primer on Partial Least Squares Structural Equation Modeling (PLS-SEM), Long Range Planning. doi:10.1016/j.lrp.2013.01.002

Henseler, J., Ringle, C.M., Sinkovics, R.R., 2009. The use of Partial Least Squares Path Modeling in International Marketing. Adv. Int. Mark. 20, 277-319. doi:10.1016/0167-8116(92)90003-4

HLPE, 2014. Food losses and waste in the context of sustainable food systems. A Rep. by High Lev. Panel Expert. Food Secur. Nutr. Comm. World Food Secur. Rome 2014.

House of Lords, 2014. Counting the cost of food waste: EU food waste prevention. House of Lords, European Union Committee, 10th Report of Session 2013-14. 
Hurst, M., Dittmar, H., Bond, R., Kasser, T., 2013. The relationship between materialistic values and environmental attitudes and behaviors: A meta-analysis. J. Environ. Psychol. 36, 257-269. doi:10.1016/j.jenvp.2013.09.003

Katajajuuri, J.-M., Silvennoinen, K., Hartikainen, H., Heikkilä, L., Reinikainen, A., 2014. Food waste in the Finnish food chain. J. Clean. Prod. 73, 322-329. doi:10.1016/j.jclepro.2013.12.057

Kilbourne, W., Pickett, G., 2008. How materialism affects environmental beliefs, concern, and environmentally responsible behavior. J. Bus. Res. 61, 885-893. doi:10.1016/j.jbusres.2007.09.016

Kline, R.B., 2011. Principles and practice of structural equation modeling, Methodology in the social sciences. doi:10.1038/156278a0

Kormos, C., Gifford, R., 2014. The validity of self-report measures of proenvironmental behavior: Ameta-analytic review. J. Environ. Psychol. 40, 359-371. doi:10.1016/j.jenvp.2014.09.003

Kosseva, M.R., 2013. Introduction: Causes and Challenges of Food Wastage, in: Food Industry Wastes. Assessment and Recuperation of Commodities. Elsevier, pp. xv-xxiv. doi:10.1016/B978-0-12-391921-2.00019-6

Langley, J., Yoxall, A., Heppell, G., Rodriguez, E.M., Bradbury, S., Lewis, R., Luxmoore, J., Hodzic, A., Rowson, J., 2010. Food for thought?--A UK pilot study testing a methodology for compositional domestic food waste analysis. Waste Manag. Res. 28, 220-227. doi:10.1177/0734242X08095348

Lucifero, N., 2016. Food Loss and Waste in the EU Law between Sustainability of Well-being and the Implications on Food System and on Environment. Agric. Agric. Sci. Procedia 8, 282-289. doi:10.1016/j.aaspro.2016.02.022

Mallinson, L.J., Russell, J.M., Barker, M.E., 2016. Attitudes and behaviour towards convenience food and food waste in the United Kingdom. Appetite 103, 17-28. doi:10.1016/j.appet.2016.03.017

Milfont, T.L., 2009. The effects of social desirability on self-reported environmental attitudes and ecological behaviour. Environmentalist 29, 263-269. doi:10.1007/s10669-008-9192-2

Mondéjar-Jiménez, J.A., Ferrari, G., Secondi, L., Principato, L., 2015. From the table to waste: An 
exploratory study on behaviour towards food waste of Spanish and Italian youths. J. Clean. Prod. 138, 8-18. doi:10.1016/j.jclepro.2016.06.018

Neff, R. a., Spiker, M.L., Truant, P.L., 2015. Wasted Food: U.S. Consumers’ Reported Awareness, Attitudes, and Behaviors. PLoS One 10, e0127881. doi:10.1371/journal.pone.0127881

Papargyropoulou, E., Lozano, R., K. Steinberger, J., Wright, N., Ujang, Z. Bin, Steinberger, J., Wright, N., Ujang, Z. Bin, 2014. The food waste hierarchy as a framework for the management of food surplus and food waste. J. Clean. Prod. 76, 106-115. doi:10.1016/j.jclepro.2014.04.020

Parfitt, J., Barthel, M., Macnaughton, S., 2010. Food waste within food supply chains: quantification and potential for change to 2050. Philos. Trans. R. Soc. Lond. B. Biol. Sci. 365, 3065-81. doi:10.1098/rstb.2010.0126

Parizeau, K., Massow, M. von, Martin, R., von Massow, M., Martin, R., 2015. Household-level dynamics of food waste production and related beliefs, attitudes, and behaviours in Guelph, Ontario. Waste Manag. 35, 207-217. doi:10.1016/j.wasman.2014.09.019

Porpino, G., Parente, J., Wansink, B., 2015. Food waste paradox: antecedents of food disposal in low income households. Int. J. Consum. Stud. 39, 619-629. doi:10.1111/ijcs.12207

Porpino, G., Wansink, B., Parente, J.G., 2016. Wasted Positive Intentions: The Role of Affection and Abundance on Household Food Waste. J. Food Prod. Mark. 4446, Forthcoming. doi:10.1080/10454446.2015.1121433

Principato, L., Secondi, L., Pratesi, C.A., 2015. Reducing food waste: an investigation on the behaviour of Italian youths. Br. Food J. 117, 731-748. doi:10.1108/BFJ-10-2013-0314

Qi, D., Roe, B.E., 2016. Household food waste: Multivariate regression and principal components analyses of awareness and attitudes among u.s. consumers. PLoS One 11, 1-19. doi:10.1371/journal.pone.0159250

Quested, T.E., Marsh, E., Stunell, D., Parry, A.D., 2013. Spaghetti soup: The complex world of food waste behaviours. Resour. Conserv. Recycl. 79, 43-51. doi:10.1016/j.resconrec.2013.04.011

Quested, T.E., Parry, A.D., Easteal, S., Swannell, R., 2011. Food and drink waste from households in the UK. Nutr. Bull. 36, 460-467. doi:10.1111/j.1467-3010.2011.01924.x

Refsgaard, K., Magnussen, K., 2009. Household behaviour and attitudes with respect to recycling 
food waste--experiences from focus groups. J. Environ. Manage. 90, 760-71. doi:10.1016/j.jenvman.2008.01.018

Richins, M.L., 2004. The Material Values Scale: Measurement Properties and Development of a Short Form. J. Consum. Res. doi:10.1086/383436

Ringle, C., Wende, S., Becker, J., 2015. Ringle, Christian M., Wende, Sven, \& Becker, JanMichael. (2015). SmartPLS 3. Bönningstedt: SmartPLS. Retrieved from http://www.smartpls.com. Retrieved from.

Secondi, L., Principato, L., Laureti, T., 2015. Household food waste behaviour in EU-27 countries: A multilevel analysis. Food Policy 56, 25-40. doi:10.1016/j.foodpol.2015.07.007

Setti, M., Falasconi, L., Segrè, A., Cusano, I., Vittuari, M., 2016. Italian consumers’ income and food waste behavior. Br. Food J. Iss Br. Food J. Br. Food J. Br. Food J. 118, 1731-1746. doi:10.1108/02656710210415703

Stancu, V., Haugaard, P., Lähteenmäki, L., 2016. Determinants of consumer food waste behaviour: Two routes to food waste. Appetite 96, 7-17. doi:10.1016/j.appet.2015.08.025

Stefan, V., van Herpen, E., Tudoran, A.A., Lähteenmäki, L., L??hteenm??ki, L., 2013. Avoiding food waste by Romanian consumers: The importance of planning and shopping routines. Food Qual. Prefer. 28, 375-381. doi:10.1016/j.foodqual.2012.11.001

Stenmarck, Å., Jensen, C., Quested, T., Moates, G., 2016. Estimates of European food waste levels.

Stuart, T., 2009. Waste: Uncovering the Global Food Scandal. Penguin books, London.

Sun, M., Trudel, R., 2016. The Effect of Recycling versus Trashing on Consumption: Theory and Experimental Evidence. J. Mark. Res. doi:10.1509/jmr.15.0574

Tonglet, M., Phillips, P.S., Bates, M.P., 2004a. Determining the drivers for householder proenvironmental behaviour: Waste minimisation compared to recycling. Resour. Conserv. Recycl. 42, 27-48. doi:10.1016/j.resconrec.2004.02.001

Tonglet, M., Phillips, P.S., Read, A.D., 2004b. Using the Theory of Planned Behaviour to investigate the determinants of recycling behaviour: A case study from Brixworth, UK. Resour. Conserv. Recycl. 41, 191-214. doi:10.1016/j.resconrec.2003.11.001

Tucker, C. a., Farrelly, T., 2015. Household food waste: the implications of consumer choice in 
food from purchase to disposal. Local Environ. 21, 682-706.

doi:10.1080/13549839.2015.1015972

UNEP, 2014. Prevention and reduction of food and drink waste in businesses and households Guidance for governments, local authorities, businesses and other organisations, Version 1.0.

Visschers, V.H.M.M., Wickli, N., Siegrist, M., 2016. Sorting out food waste behaviour: A survey on the motivators and barriers of self-reported amounts of food waste in households. J. Environ. Psychol. 45, 66-78. doi:10.1016/j.jenvp.2015.11.007

Watson, M., Meah, A., 2012. Food, Waste And Safety: Negotiating Conflicting Social Anxieties Into The Practices Of Domestic Provisioning. Sociol. Rev. 60, 102-120. doi:10.1111/1467954X.12040

WRAP, Programme, R., Waste, F., Report, F., WRAP, 2007. Food Behaviour Consumer Research : Quantitative Phase.

WRAP, Quested, T., 2009. Household Food and Drink Waste in the UK A report containing quantification of the amount and types of household.

Xu, D.Y., Lin, Z.Y., Gordon, M.P.R., Robinson, N.K.L., Harder, M.K., 2016. Perceived key elements of a successful residential food waste sorting program in urban apartments: stakeholder views. J. Clean. Prod. 134, 362-370. doi:10.1016/j.jclepro.2015.12.107

Zorpas, A.A., Lasaridi, K., 2013. Measuring waste prevention. Waste Manag. 33, 1047-56. doi:10.1016/j.wasman.2012.12.017 